\title{
WHY EVERY REALIST SHOULD BE A PLATONIST
}

LARRY LEE BLACKMAN

My thesis ${ }^{1}$ is very simple: every realist should be a Platonist. By the term "realist" I mean anyone who believes that universals exist. By "Platonist" I mean anyone who thinks: (1) that universals are not in space and time and (2) that there are uninstantiated universals. Hence, my claim is that anyone who believes that universals exist ought also to admit that universals are not in space and time and that there are uninstantiated universals.

However, questions arise. What, for example, is the nature of a universal? It might be thought that the very idea of a universal is that of an entity not in space and time, so that anyone who identified universals with things in space and time could hardly be said to believe in the existence of universals. What, then, could the suggestion that universals are in space and time mean? Similarly, it might seem that a commitment to the existence of universals in its very nature involves belief in uninstantiated universals. If not, what would the claim that there are universals amount to?

If one thing is clear, it is that we must get straight on just what belief in the existence of universals does and does not entail. I will not, therefore, argue at any great length for the existence of universals. Rather, I will try to show what someone who claims that universals exist is trying to do, and I will attempt to clarify the concept of a universal. It will then be open to anyone either to accept or reject the claim that universals exist. It seems to me, indeed, that a proper understanding of the nature of a universal makes belief in the existence of universals-and by this I mean Platonic universals--virtually unobjectionable. But whether anyone with what I would 
like to call a proper understanding of the nature of a universal chooses to accept or to reject the existence of universals is a topic I will not pursue.

My strategy will be the following: first, I will indicate, however briefly, what the realist is attempting to do when he claims that there are such things as universals. Second, I will try to say what universals are at least supposed to be. The bulk of the paper will be given over to a discussion of the question whether universals are in space and time. I will argue that anyone who admits the existence of universals in any sense ought to admit the existence of entities not in space and time which are "independent" in the Platonic sense.

What the realist is attempting to do, I believe, is to account for the fact of sameness. Or, to say the same thing in different words, he is attempting to give an ontological ground for the phenomenon of sameness. That sameness exists seems to ine to be incontrovertible. Even if individual objects are one and all particular, so that each is numerically different from all the others, different objects may share common features. Two different objects may both be colored blue and are therefore in $a$ genuine and important sense the "same." Moreover, if all blue objects were suddenly to disappear, it would always be possible at some later time for another object to bear the "same" blue quality. One way of viewing the enterprise known as ontology is as an attempt to give an account of such obvious phenomena as sameness and difference. In the tradition that goes back at least to Plato, phenomena are accounted for, or given an ontological ground, by claiming that they represent categories of reality. When the realist claims that universals exist, he is merely trying to say that many things seem to exhibit the phenomenon of sameness or that sameness is a fundamental feature of the world, and he is attempting to capture the plienomenon by means of a category.

Whether one agrees that this is what the realist is trying to do, or even that the realist is right in trying to do it, there is obvious disagreement concerning the nature of a universal. In recent times some philosophers have claimed that universals are in space and time. This is significantly different from the Platonist's view, since there is clearly a great difference between entities which are in space and time and those which are not. It is strange that both should be claiming the existence of universals when 
they are apparently attaching such different meanings to the word. Still, the recent philosophers do claim that universals exist, so there is perhaps some justification for their claim to be realists. In order to distinguish their position from that of the Platonists, and for reasons which will become clear, let us call such philosophers "empiricist realists."

For a better grasp of the difference between the two views, let us consider, first of all, the platonist or "traditional" view in more detail. Whether plato himself ever held the view is contentious, but, fortunately, what Plato actually thought is not as important for us as the more or less coherent position usually ascribed to him. For that matter, there is not even unanimity on the "platonic" view, but for our purposes it may be taken to be the following: Assuming two ordinary blue squares at places $p_{1}$ and $p_{2}$ at time $t_{1}$, the quality blue, which charactertzes the object at $p_{1}$ is said to be an instance of the universal "blueness," and the same thing holds for the quality characterizing the object at $\mathrm{p}_{2}$. Universals are not in space and time. The instances, which are in space and time, differ numerically, but they are all instances of the same universal, which itself is outside space and time. The relationship between a universal and one of its instances is that of "participation" or "imitation;" all blue things participate in, or imitate, blueness. Alternatively, it is "in virtue of" the universal that an instance is what it is; it if in virtue of blueness that all instances of blueness are blue. The universal, in short, provides an explanation, in the sense of an ontological ground, for why individual things are what they are. Furthermore, according to the view under consideration, universals are "independent." The existence of any given universal does not depend on the existence of anything else, and certainly not on that of any of its instances. Of course, this opens the door to the possibility of "uninstantiated universals," that is, universals which never have instances anywhere, and, indeed, Platonism holds the existence of uninstantiated universals. Finally, usually associated with the Platonic view is the notion that it is impossible to "perceive" universals in any ordinary sense of the term; rather, they are objects $8^{\mathrm{f}}$ "intuition,"

In contrast, the empiricist realist holds that exactly the same blueness is in $p_{1}$ and $p_{2}$ at $t_{1}$. Literally the same thing is in different places at the same time, or if you prefer, the universal blueness is 
identified with the quality blue. Instances of universals do not exist, because the claim that there are instances would mean that there is an inherent difference between the instance and the thing the instance is an instance of, namely, the universal, and this is precisely what the view in question wishes to deny. Since there are no instances, there is no problem in regard to the relationship between a universial and its instances, although there are, of course, problems concerning the relationships anong various universals and, also, concerning the relationship between universals and particulars, if these latter are thought to exist. ${ }^{2}$ Universals are not independent, nor, obviously, are there uninstantiated universals. It also appears to be compatible with this view, although it does not necessarily follow from it, that at least some universals are accessible to sense perception. One can see blueness and squareness. Whether all universals are accessible to perception must remain open to question, because mental awarenesses, such as believings and wonderings, are sometimes taken to be universals, and it is at least doubtful that these are apprehended by perception. Direct acquaintance, in contradistinction to perception, is a mode of awareness which would seem to apply equally to qualities of objects and mental awareness.

Various considerations support the view that universals are in space and time. For some philosophers, it would seem, there is an apparent absurdity in claiming that blueness is not the object of sense awareness, so that universals must be in space and time. Nicholas wolterstorff, for example, in criticizing the belief that "universals are indifferent to the buzz of space and time," argues that:

if we can point to and percieve universals, then universais must be locatable. The basis of the traditional doctrine is, I suppose, a vague intuition of the fact that places and times play no role in determining the identity of universals. But of course it does not follow from this that universals are outside of space and time. Greenpess does appear at certain times and places.

To the Platonist, however, Wolterstorff's argument appears to beg the question. It seems to be the following: 
(1) If we perceive universals, they are in space and time.

(2) We perceive universals.

Therefore universals are in space and time.

One who holds the traditional doctrine might point out that (2) presupposes the very point at issue. If one refuses to grant beforehand that universals are in space and time, the claim that we perceive universals is much less plausible.

Similarly, there is an argument to the effect that universals are in space and time because their exemplifications are. According to Alan Donagan,

there is strong reason for thinking that if universals are exemplified in space and time, they are where they are exemplified. You can verify the statement that Russell is in his room by looking into it and seeing him there. When you look, you see not only $7^{\text {him }}$ and his room, but also that he is in it.

Again, however, the Platonist finds that the argument begs the question.

It seems to be:

(1) If universals are exemplified in space and time, they are in space and time.

(2) Universals are exemplified in space and time. Therefore, universals are in space and time.

When Donagan says that universals are "exemplified" in space and time, he probably means nothing more than that the instances of universals, if there are such, are in space and time. The platonist, however, would be unconvinced that (2) is true. While he would probably be willing to grant that qualities are in space and time, there is little reason to suppose that he would allow the identification of a quality and a universal, since it begs the point at issue. Even if qualities are exemplified in space and time, unless qualities are universals it does not follow that universals are exemplified in space and time.

The arguments advanced by Wolterstorff and Donagan are unimpressive. There are, however, other arguments 
to show that universals are in space and time-arguments which take the form of criticisms of the traditional view. If the view that universals are not in space and time is shown to be seriously deficient, the position taken by Wolterstorff and Donagan should be taken more seriously, even if the arguments they give are unconvincing.

In the first place, then, universals not in space and time are supposed to be unitary. Blueness, for example, is one thing. But then a doubt arises as to the genuine universality of a universal. If a universal is one thing and quite apart from all its instances, is it not itself particularized? Thus, Donald Brownstein, for example, attríbutes to platonism the view that:

large things are, though in a deficient way, like Largeness, i.e., they are large. Beautiful things are, though deficiently, like Beauty itself, i.e., beautiful. To partake of F-ness is to be, though deficiently, like Fness.

But then he asks,

What, to paraphrase Berkeley, could be like one particular large thing but another particular large thing? To object that Forins [that is, Platonic universals] are not things misses the point, which is that they are particulars. Perhaps they are superparticulars, having those qualities that they do in some superior manner, byt they are no less particular for all that.

Brownstein's argument depends on the supposition that an instance of a universal is something like the universal itself, which is reinforced by the Platonist's characterization of the relation between the two as that of "imitation." If particulars imitate universals, they must in some degree be similar to universals. It then seems hard to escape the conclusion that a universal, like a particular, is one thing and hence not universal at all. Brownstein thinks the only view which does justice to the universality of universals is one which places them squarely in space and time. Whether he is correct in thinking this remains to be explored, but in any event the question he raises is interesting. 
universal which is one thing appears to lose something of its universality.

If, on the other hand, we take very seriously the notion that instances are in space and time and universals are not, it turns out that there is a very great dissimilarity between the two kinds of things. And whole new problems emerge. First, there is a problem determining the nature of the entity not in space and time. Blueness itself is not blue, since entities outside space and time are presumably colorless. Why, then, is the predicate used to describe the thing in space and time also employed to characterize the thing outside space and time? What, in short, is the point in calling the universal "blueness?" If the entity denoted by "blueness" has none of the characteristics of things in space and time, the inappropriateness of describing it in terms of spatially-temporally bound predicates is obvious. But we are then seemingly at a loss to say what a universal is. Second, sooner or latef we must face the "classical difficulty" of Platonism. I0 If instances of universals are in space and time and universals are not, it is very difficult, if not impossible, to determine the relationship between the two. The locutions "participate in" and "imitate" are sometimes employed; instances are said to "participate in" or to "imitate" universals. But the nature of "participation" or "imitation" is never made clear. What does it mean to say that something in space and time "participates in" or "imitates" something not in space and time? According to A. D. Woozley, the problem is "not almost impossjbly difficult to solve but in principle insoluble." 1 Woozlely's claim may be too strong, for things in space and time may indeed be related in one way or another to things not in space and time, and it may be possible for us more or less adequately to describe the relationship(s). It is, however, difficult. Third, the question is at least worth considering whether anything not in space and time should really be characterized as being universal, the term "universal" seemingly having to do with places and times. The whole point in calling a universal a universal would seem to be that it is the sort of thing which appears in various places at the same time. The view which claims that universals are outside space and time appears either: to ignore or to blur this insight.

Our dilemma is that if, on the one hand, the similarity between universals and instances is emphasized, universals, being particularized, are no longer universals. On the other hand, if the 
difference between universals and instances is maximized, we no longer understand the nature of a universal, nor is the relationship between universals and instances at all clear, nor does the employment of the term "universal" seem faithful to what appears to be the root meaning of the word.

We do not yet have a convincing argument showing that universals are in space and time, but there are clearly great difficulties in assuming that they are not. More positively, the inadequacies of Platonism may be taken to reveal what a more satisfactory account of sameness would have to accomplish. It would have to do justice to the universality of the phenomenon. Qualities can be in different places at the same time, and this important fact must not be forgotten. The fact that the qualities which constitute the phenomenon of sameness are themselves in space and time must be taken seriously. Furthermore, if there are entities not in space and time, the nature of these entities nust be more fully explicated and the relationship of qualities to these entities more clearly specified.

Although, as we have seen, there are difficulties associated with the traditional view, for a better understanding of what the Platonist is trying to say let us consider arguments designed to show that universals are not in space and time. The primary consideration in this regard seems to be that certain things in space and time need accounting for and the account is not to be had in terms of the things in space and time themselves. It is chiefly the phenomenon of sameness which concerns us here, so let us turn our attention more specifically to it.

First, there is the above-mentioned fact that the same quality can exist in different places at the same time. To give this phenomenon a name, let us call it "ubiquity," realizing that in the strict sense a quality such as the quality blue may not be ubiquitous. It is ubiquitous enough for our purposes. The question therefore arises: What accounts for ubiquity? In virtue of what are all blue things blue? How is it possible that different blue things can be blue at the same time? A causal answer is not expected, and one who insists on viewing the matter in this way will find only grief and befuddlement. Rather, the question invites a more general, descriptive account of the phenomenon, and it is the platonist realist's contention that all blue things are blue and it is possible for different things to be blue at the same time because of the existence of a certain universal. 
Perhaps less opaquely, they all fulfill the condition(s) for a thing's being blue. Wherever and whenever there are blue things, they are blue in virtue of their fulfilling certain conditions, whatever conditions are involved in something's being blue, and these conditions are what the Platonist is calling attention to with the word "blueness." No one would ever think that the conditions themselves are in space and time, and hence we arrive at the platonist's conclusion that universals are not in space and time.

A second characteristic of the phenomenon of sameness is that of repeatability. Not only is it possible for many blue things to exist at the same time, but they may also do so at different times. There is, to be sure, nothing remarkable about different things existing at different times, but, as we are accustomed to thinking, the same object does not go out of, and then return into, existence. Qualities do this. If all blue things were suddenly to disappear, it would always be possible for the same blue quality to recur. Qualities are repeatable, and this fact cries out for an account. platonist relaists, then, point to the universal as accounting for this phenomenon. In other words, the possibility exists that the quality blue may be instantiated in different places at different times even if, at any given time, it may be instantiated nowhere. And this possibility exists. Light is shed on the meaning of the claim that universals are not in space and time when it is realized that one who says this is identifying universals with possibilities and taking very seriously the existence of possibilities. Realists of this sort are claiming that universals are possibilities, that possibilities are not in space and time, and that it is in virtue of certain possibilities that the phenomenon of repeatability is to be accounted for.

Whether conditions are identical with possibilities is, for our purposes, perhaps moot. The Platonist wants to identify them, because a universal is supposed to be unitary. Little harm would seem to be done if we allow that the thing that accounts for ubiquity also provides the ground for repeatability. on the other hand, if someone were to insist on two different kinds of universals, each grounding its own particular phenomenon, I, for one, would have no qualms in admitting it. of greater significance is that, for the Platonist, these conditions or possibilities with which universals are identified do not themselves exist in space and time. 
While there are other arguments designed to show that universals are not in space and time, the foregoing are some of the more interesting arguments, or at least some of the ones more frequently advanced. It is my hope to have clarified what the platonist is trying to say.

We have examined arguments favoring the view that universals are in space and time and also those supporting the view that they are not. And we have considered objections to Platonism. In the interest of fairness, we ought to ask if there are criticisms of the empiricist's position.

The independence thesis might be thought to count against the empiricist's view. One who claims that universals are in space and time must admit that universals come into, and pass out of, existence. And this contradicts the independence thesis. For his part, however, the empiricist might suggest that one of the problems with the traditional view is the independence thesis and that there is really nothing odd about the constant exits and entrances of universals. We also ought not to forget that the emiricist refuses to countenance the notion of uninstantiated universals, which the independence thesis seems to entail.

Most damaging to the empiricist's position is that it fails to provide an ontological ground for sameness. Although, to his credit, he never loses sight of the ubiquity of qualities or denies the fact of repeatability, the proponent of the view that universals are in space and time never really provides a genuine account for these phenomena. Thus Brownstein, for example, in his admirable Aspects of the Problem of Universals, argues that qualities are universals, and by this he means that they are identical. 12 Brownstein effectively demolishes both nominalism, 12 which may be viewed as the attempt to deny the phenomenop ${ }_{3}$ of sameness, and the thesis of perfect particulars, 13 which attempts to ground the sameness of qualities in a relation of exact similarity. As we have already observed, he finds fault with a Platonism which pays only lip service to the ubiquity of qualities. However, perhaps paradoxically but perhaps also for reasons we can understand, one searches in vain for something like an account of ubiquity. Conditions and possibilities, as I have developed these notions, or anything remotely like them, are not even hinted at. Therefore, the Platonist can claim that the position ultimately fails 
to provide a ground for sameness. If one merely identifies a quality with a universal and leaves the matter at that, why make the identification to begin with?

We would appear to be at an impasse. In the empiricist's view, the Platonist fails to do justice to the ubiquity of qualities. According to the platonist the empiricist fails to ground the ubiquity and repeatability of qualities. Furthermore, the two views seem to be resolutely incompatible with one another, since, clearly, universals are either in space and time or they are not. Perhaps, we ought to take another tack, holding in abeyance the criticisms of the respective positions and considering their advantages instead.

Advantages of the empiricist viewpoint are, first, that universals are not particularized, so that what the empiricist calls a universal appears to be more genuinely universal. Second, it does not encounter the criticism that the entity it calls a universal has none of the characteristics of things in space and time, but yet is described in terms of spatially-temporally bound predicates. Blueness really is blue, in the empiricist's view. Third, since instances do not exist, the empiricist does not have to worry about the relation between a universal and its instances. Hence, the position escapes the "classical difficulty" of platonism. Fourth, the empiricist's view seems to take more seriously the idea that the term "universal" really concerns things in places and times. The position pays due respect to the ubiquity of qualities and, once again, seems to have more genuine claim to what would appear to be the root meaning of the term. I4

The one, but not inconsiderable, advantage of platonism is that it makes a more forthright attempt to provide an ontological ground for sameness. If the characterization suggested earlier of what the realist is trying to do is correct, then, perhaps contrary to his expectations, the empiricist finds himself with a conspicuous hole in his theory--a failure to account for the phenomenon. Whether or not the platonist succeeds in accounting for it, he at least makes a more robust attempt.

Why does the empiricist make a less robust attempt? The reasons, I suggest, are at least two, an examination of which reveals the most fundamental difference between the two positions. 
One of these is that the empiricist is, after all, an empiricist, so it should not come as too great a surprise to discover that the battle is joined over the empiricism/rationalism issue. A comnitment to rationalisin does not, of course, entail belief that universals are not in space and time, but the rationalist will at least not feel too uncomfortable with Platonism. If universals are not in space and time, they are not known on the basis of sensory experience. One who grants ontological status to conditions and possibilities does so on the basis of the dialectic. As we have seen, it is by means of a process of reasoning, not sense experience, that the Platonist arrives at the existence of such things. One argues that conditions and possibilities account for the phenomena of ubiquity and repeatability. In so doing, he provides a "transcendental argument," which I will understand as an argument intending to establish the existence of an entity or entities on a priori considerations alone. Typically, a transcendental argument proceeds by claiming that if such and such an entity did not exist, then certain phenomena would not be as they are. But the phenomena are as they are, and therefore such and such an entity does exist. Empiricists have usually been suspicious of claims concerning the existence of entities not accessible to direct acquaintance, and they have characteristically been wary of transcendental arguments. The reluctance to grant the existence of platonic universals may be traced in part to the very empiricism of the empiricist. As in the case of rationalism, a commitment to empiricism does not entail belief that universals are in space and time, for one might want to deny the existence of universals altogether. But the empiricist will probably find the view more congenial., since qualities are accessible to sense experience.

A second and related reason for the empiricist's skepticism may have to do with the terminology often employed by the Platonist. The Platonist speaks of "entities" or "things" which are not themselves in space and time and which have none of the characteristics of things in space and time. Nonetheless, they are said to "account for" certain phenomena in space and time. Blueness is supposed to account for the fact that all blue things are blue. Or, worse yet, blue things "participate in" or "imitate" blueness. All of this sounds odd to the empiricist's already sensitive ear, for what the platonist seems to be doing is intropucing "queer and weird entities, things best shunned." The Platonist, in short, appears to be guilty of a hypostatization. 
And the fear of a hypostatization is quite evidently related to the suspicion of entities not accessible to acquaintance. One who is already inclined to trust only the evidence of the senses, and perhaps not even that very much, will most assuredly be disinclined to accept claims asserting the existence of "things" which are not even in principle capable of being objects of acquaintance.

The interesting questions, then, concern the relative viability of empiricism and the appropriateness or inappropriateness of the terminology of Platonism.

Let us treat the latter question first. More specifically, does Platonism involve a hypostatization? A hypostatization would be involved only if the terms "universal," "participates in," etc. designated only ideas or concepts, perhaps construed as peculiarly mental entities, but with no objective referents. clearly, the Platonist will be unwilling to admit that these terms lack objective referents, so perhaps the question is whether the platonist is able to state his case in a less objectionable manner. That is, can he present what he believes to be the facts of the matter without invoking the more traditional terminology? If the analysis offered earlier is correct, the question whether universals exist is the question whether conditions and possibilities exist, so what we want to know is whether the platonist is guilty of a hypostatization in regard to these things. Can the empiricist admit that conditions and possibilities exist?

First, let us retreat one step and inquire concerning the areas in which the empiricist and the platonist already seem to agree. They both admit the fact of sameness; they do not dispute the phenomena of ubiquity and repeatability. There is, moreover, no conflict over the idea that phenomena are to be accounted for. Neither denies, in other words, that there are qualities and that upon reflection certain facts about qualities emerge which are to be grounded ontologically. The only apparent difference is that what the platonist calls an instance, the empiricist calls a universal. But they do not disagree with what the terms "instance" and "universal" denote. They do not, that is, deny that there are things in space and time which display certain interesting characteristics. The difference between the platonist and the empiricist at the level of objects in space and time, I am suggesting, is merely terminological. But if this is 
so, then at least, here the empiricist has no real quarrel with the Platonist. Let us see if the same thing may be said at the level of things outside space and time.

Following our adopted strategy, we are putting the question not in terms of whether Platonic universals exist, but in what are hoped to be more familiar, less metaphorical, terms. What we want to know is whether the empiricist can grant that conditions and possibilities exist. The answer to this question is relatively straightforward: A strict empiricist will be unable to admit that conditions and possibilities exist. A strict empiricist will be unable to admit the existence of anything which in principle is not an object of direct acguaintance, nor is he able to accept the legitimacy of transcendental arguments. Someone of this persuasion will be unable to admit that conditions and possibilities exist, or, which is to say the same thing, he must deny the existence of platonic universals. It turns out, then, that the difference between the two views concerning things not in space and time is not merely terminological, for even with the less objectionable nomenclature the strict empiricist has a real disagreement with the platonist.

What this also means, is that the strict empiricist fails to provide an ontological ground for the phenomena. This would obviously not be viewed as a problem by anyone who would try to deny the legitimacy of the entire ontological undertaking. But the empiricist realist, we remember, is already committed to an attempt to account for the phenomena. The empiricist has adinitted all along that there is a fact of sameness, that ubiquity and repeatability exist, and that these things are to be accounted for. So he must own up to what we have already seen to be the serious objection to the empiricist position. The suggestion was made that Brownstein's view, for example. ultimately fails to provide a ground for sameness, and if this is true of Brownstein's view, this is true of the empiricist view in general. A position which in the end overlooks conditions and possibilities. or something like these, fails to account for the phenomena.

It is not my intention to criticize a stringent empiricism. However, the empiricist realist may, 1 believe, at least consider the possibility that if a stringent empiricism is incompatible with the ability to carry through an analysis of sameness, it may be the 
empiricism, not the attempt to ground the phenomenon, which is fundamentally misguided.

The empiricist must disavow either a strict empiricism or the ontological undertaking itself. Let us assume it is the former. Then it may turn out that the empiricist is able to buy into the substance of what the Platonist is claiming while perhaps rejecting his terminology. If universals are really conditions or possibilities and the empiricist can be convinced that these latter account for phenomena he has already admitted exist, a functional equivalence between his view and that of the platonist is revealed. It has already been suggested that what the empiricist calls a "universal" the Platonist calls an "instance," and actually the same thing is denoted by both terms. It now emerges that if the empiricist is willing to make an important concession, it can be granted that what he calls a condition or a possibility a Platonist calls a universal, but that the terms "condition," "possibility," and "universal" actually refer to one and the same thing. The difference between the two positions will be merely a difference in terminology.

Nomenclature is, however, important. The empiricist may be better able to grasp other aspects of Platonism if they are put in terms of a less forbidding terminology. Construing universals as conditions or as possibilities coheres nicely, for example, with the Platonist's independences thesis. Qualities may come and go; conditions, or possibilities, exist independently. An uninstantiated universal, then, is simply an unfulfilled condition, or set of conditions, or an unrealized possibility. It is probably important also to mention that it is not really the responsibility of the platonist to name any uninstantiated universal. One is presumably able to name a universal only on the basis of an acquaintance with one or more of its instances. The fact that we are unable to name any uninstantiated universal does not count against the Platonist's claim that such things exist. The claim is merely a reflection of the independence of conditions or possibilities.

Similarly, viewing a universal as a condition, a set of conditions, or a possibility, helps to clarify the relation between the entity which is in space and time and that which is not. It is merely that of a fulfillment of a condition, or a set of conditions, or a realization of a possibility. This terminology may be viewed as an improvement on the Platonist's "participation" or "imitation," because it is less 
metaphorical. Actually, talk of "participation" or "imitation" ought to be abandoned if for no other reason than that it leads one to think that universals are similar to their instances. If the above analysis is correct, a universal is nothing at all like an instance. Universals themselves are not universal; they account for a universal phenomenon, that of sameness. The "classical difficulty" of platonism is not thereby "solved," for it remains to be shown more precisely just what sort of relation a relation is which relates an entity in space and time witl one which is not. clarification is needed on what, exactly, it means to say that universals "account for" sameness. But it is hoped that the language of "conditions," "fulfillment," etc. at least aids the empiricist in understanding the Platonist's claim.

Even more, the degree of understanding should be sufficient to enable him to see that he, too ought to be a Platonist. Why is it, then, that every realist should be a Platonist? Every realist should admit the phenomenon of sameness, that is, he should admit the facts of ubiquity and repeatability. He should also admit the existence of conditions and possibilities which ground ubiquity and repeatability. He should admit the independence of conditions and possibilities. And that makes him a Platonist.

A tentative suggestion explaining why some realists are not Platonists is that they find theinselves more or less loosely associated with a tradition that claims adherence to a "Principle of Acquaintance," according to which any candidate for an ontology must be an object with which we are directly acquainted. These philosophers are the heirs of a truncated form of logical positivism, which on strict empiricist grounds attempted to deny the meaningfulness of metaphysics altogether. The dilemma in which they now find themselves is that they attempt to do metaphysics while still claiming allegiance to an empiricism which undermines the very enterprise. As far as I am able to determine, they are only vaguely aware that they are confronted with a dilemma. If the foregoing paper has succeeded in showing anything at all, it is, I hope, that the empiricist realist has not yet entirely rid himself of the shackles of positivism.

I have argued that every realist should be a Platonist, but not, it should be noted, that everyone who thinks about these matters should be a realist. of course, nominalism, which is the attempt to deny that the phenomenon of sameness exists, seems to me so 
absurd as to scarcely deserve mentioning. And if anyone would deny the legitimacy of the ontological undertaking itself, the burden of proof is on him to produce arguments showing its illegitimacy.

State University College, Geneseo, New York 
NOTES

${ }^{1}$ I am indebted to my colleague, Professor William Edgar, and to my former colleague, Professor stewart Umphrey, for stimulating my interest in the problem of universals. Some of the ideas here presented were originally theirs. They are not, however, responsible for mistakes made in the paper.

${ }^{2}$ Cf. the view of A. D. Woozley: "Generality is an essential feature of the objects of experience, recognition of generality is an essential feature of experience itself, and reflection of this generality is shown in the vocabulary of any language, all the words of which (with the exception of proper names) are general." A. D. Woozley, "Universals," The Encyclopedia of Philosophy, Vol. 8 (Ed. Paul Edwards. New York: Macmìllan Publishing Co., \& The Free Press, 1967), p. 194 .

${ }^{3}$ Woozley, p. 196 .

${ }^{4}$ Gilbert Ryle, "Plato," The Encyclopedia of Philosophy, Vol. 6 (Ed. Paul Edwards. New York: Macmillan Publishing Co., \& The Free Press, 1967), p. 322 .

${ }^{5}$ A particular of this sort would be a "bare particular," or a substratum--something which is the bearer or ordinary qualities, but which is not ilself characterized by any ordinary qualities. Notice that I am distinguishing between an instance of a universal and a particular. The platonist identifies the quality with the instance, and the empiricist identifies the quality with the universal. Either philosopher may hold, in addition, that particulars exist. If the Platonist does, he then has to explain the relation(s) between instances and particulars, while the empiricist must account for the relation(s) between universals and particulars. Unless I am mistaken, the question 
whether particulars exist is unaffected by the position taken with regard to the nature of a universal.

${ }^{6}$ Nicholas Wolterstorff, "Qualities," Universals and Particulars: Readings in Ontology (Ed. Michael $\mathrm{J}$. Loux. Garden City, New York: Doubleday \& Company, Inc., 1970), p. 104 .

${ }^{7} \mathrm{Al}$ an Donagan, "Universals and Metaphysical Realism," in Universals and Particulars: Readings in Ontology (Ed. Michael J. Loux. Garden City, New York: Doubleday \& Company, Inc., 1970), p. 137.

${ }^{8}$ Donald Brownstein, Aspects of the Problem of Universals (Lawrence, Kansas: University of Kansas Press, 1973), p. 60.

${ }^{9}$ Brownstein, p. 60 .

${ }^{10}$ Cf. Donagan, pp. 136-42.

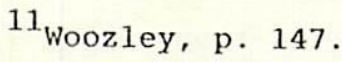

12 Brownstein, passim.

13 Brownstein, p. $17 \mathrm{ff}$.

${ }^{14}$ In fairness, the platonist really does not deny the ubiquity of qualities, for that is what, with his notion of a universal, he is trying to account for. The empiricist is claiming that the Platonist's universals are not themselves ubiquitous.

15 wolterstorff, p. 103.

16 This is the response to Brownstein. A universal is one thing without being "one thing" in the sense that a particular is. 